\title{
Cranio-facial morphology and obstructive sleep apnea: the role of dento-facial orthopedics
}

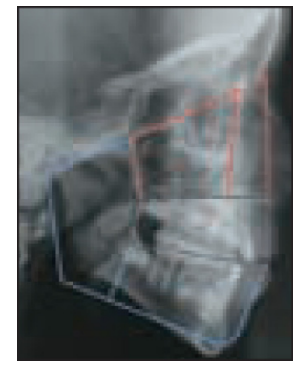

\author{
Julia COHEN-LÉVY, Philippe CONTENCIN, \\ Vincent COULOIGNER
}

\begin{abstract}
Orthodontists, thanks to their keen appreciation of facial morphology and their skills in making functional examinations, are ideally placed to detect breathing problems in their patients that can require an ENT assessment, with special attention paid to the evaluation of sleep patterns. After a site of obstruction, resulting from a soft tissue anomaly and/or a narrowing of the airway passage through bone, has been established, orthodontists may be called upon to undertake corrective treatment sometimes in conjunction with a surgical procedure.
\end{abstract}

\section{KEYWORDS}

Obstructive sleep apnea syndrome

Child

Craniofacial growth

Adeno-tonsillar hypertrophy

Oral appliance. 


\section{1 - INTRODUCTION}

Various estimates ranging from $3.2 \%$ to $30 \%$ have been presented of the extent of habitual snoring in the child population and on the $0.7 \%$ to $10.3 \%$ who suffer from obstructive sleep apnea syndrome (OSAS), as defined by the recurrence of complete obstruction (apnea) or partial obstruction (hypopnea) of the upper airways during sleep ${ }^{1,14,19}$.

This pediatric form of OSAS, which can affect newborns as well as adolescents, has a patho-physiology that differs from the adult variety, and is particularly hard to detect ${ }^{11,27}$. While it is true that only a polysomnograph recording can indisputably establish the diagnosis of sleep apnea, the paucity of sleep laboratory services make this tool available to just a small percentage of possible patients. In addition, the symptoms of OSAS are variable, not widely known, and depend on the child's stage of growth and development. (the reader may want to refer to the article on "How to detect OSAS" in this issue).

The primary cause of OSAS is an anatomical narrowing of the upper airways affecting both the soft tissues and cranio-facial structures. Defects in local neuro-muscular control, with accompanying loss of tone of the dilating muscles of the pharynx, can also play a role in causing OSAS or intensifying the effects of the morphological anomalies in some cases.

These interrelationships between cranio-facial anatomy and OSAS have frequently been described in adults, but only recently have investigators taken a lively interest in its occurrence in children, with some emphasis being placed on the role orthodontists can play as members of the inter-disciplinary medical research teams studying this ailment.

Collaboration between specialties is not limited to research and diagnosis, but continues in the application of the therapeutic sequence with orthodontic appliances like rapid palatal expansion and mandibular advancement often being indicated in early treatment procedures.

We illustrate this article, which reviews contributions published in pediatric OSAS literature on cranio-facial morphology, with clinical cases treated by a team of an ear, nose and throat (ENT) surgeon, a physician specializing in sleep disorders, and an orthodontist. We then discuss the current protocols for the treatment of OSAS, focusing on the participation of specialists in dento-facial orthopedics.

\section{2 - CRANIO-FACIAL ABNORMALITIES AND RISK FACTORS IN OSAS}

\section{2 - 1 - Non-syndromic cranio- facial abnormalities}

In addition to the pathological disturbances that create a thickening of the mucosa of the upper airways (such as mucopolysaccharidosis, the Prader Willi syndrome, and obesity with fatty infiltration of the pharyngeal walls, can reduce the diameter of the 
ventilatory pathway), examiners may also detect certain anatomic obstacles in an ENT examination.

\section{$2-1-1$ - Nasalfossae and the rhino pharynx}

- choanal stenosis or atresia;

- nasal septum anomalies like scoliosis, hypertrophy of the inferior turbinates; tissue;

- hypertrophy of adenoidal soft

- pharyngeal tumor.

\section{2 - 1 - 2 - Oral cavity, oropharynx and hypopharynx}

- hypertrophy of the palatal and lingual tonsils;

- cranio-facial anomalies, with mediofacial hypoplasia, small or retruded mandible, which force the tongue to intrude on the oropharynx ${ }^{13}$;

- true macroglossia (arterio-veinous or lymphatic malformation, von Recklinghausen neurofibromatosis ...).

For the majority of children who suffer from the OSAS syndrome, the principal etiological factor is hypertrophy of lymphoid tissue, which can be treated effectively with tonsillectomy or removal of adenoid tissue ${ }^{18}$. However, Guilleminault et al. ${ }^{10}$, who reviewed the records of 400 children whose tonsils and adenoids had been removed, have found that in $14.5 \%$ of these cases (case 1) problems with breathing during sleep persisted. In this study the patients who were "nonresponders" to surgery had narrow pharyngeal spaces, an under-developed maxilla, and/or a retruded mandible.
This same group described a facial phenotype of children who were at increased risk of obstructive sleep breathing difficulties, that comprised $34 \%$ of the patients with apnea. Some of the characteristics of this group were a retruded mandible, a hyper-divergence of the mandible with an increase in the cranio-mandibular, intermaxillary, and gonial angles; an elongated face; and a deep hard palate and a long soft palate (case 2). These results were confirmed by other authors ${ }^{2,28}$ : while Rees et al. ${ }^{26}$ emphasized, instead, the association with micrognathia and retrognathia. Kawashima et al. ${ }^{17}$ affirmed that apnea patients with heavily enlarged tonsillar tissues had, in comparison to control groups, more retruded mandibles and a greater increase in lower facial height.

The malocclusions most frequently described in association with OSAS are unilateral or bilateral cross bites, open bites with a low tongue position and a posterior rotation of the mandible ${ }^{7,32}$. One recent study ${ }^{25}$, comparing a group of children who snored infrequently to a group of children suffering from OSAS, found significant differences between the two: children with sleep apnea had greater incisal overjet and less overbite, narrower upper arches, and shorter lower arches than children in the control group.

\section{2 - 2 - Syndromic abnormalities}

Some of the cranio-facial malformations that occur in the apnea syndrome predispose afflicted children to a collapse of the upper airways often making early treatment essential ${ }^{15}$. In severe cases, children only a few days old must be operated on immediately 
a




C

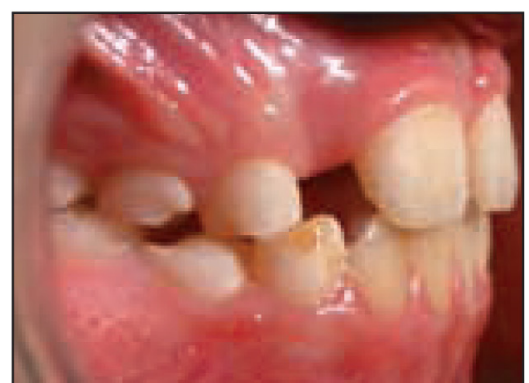

d

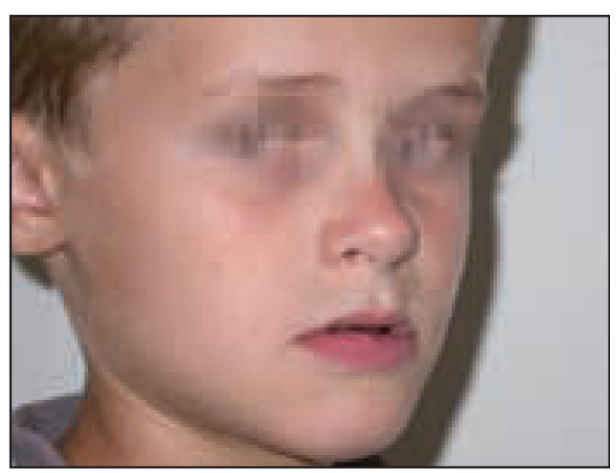

This 8 year-old boy, had persistent OSAS symptoms

despite already having had an adeno-tonsillectomy.

a: on the lateral cephalogram, a nasal septum deviation can be seen together with asymmetry of the base of the nasal fossae.

b: on the lateral cephalogram, a decrease in the size of the respiratory pathway seems to be localized behind the tongue, where there is hypertrophy of the lingual tonsillar tissues, or a retro-positioning of the tongue. This patient seems to have a Class III tendency which would make mandibular advancement inadvisable.

$c$ and d: on intra-oral examination, the palate was seen to be narrow and highly arched, with abnormal transverse relationships, an anterior infraclusion with insufficient space for the eruption of the upper lateral incisors.

e: the appearance of the boy's face was consistent with mouth breathing and a rounded lips apart posture at rest. In order to attempt to reduce the residual IAH, a turbinectomy, ablation of the lower nasal turbinate, and rapid palatal expansion were planned.

or helped to breathe with mechanical devices.

\section{2 - 2 - 1- Syndromes involving the maxilla}

The Crouzon, Apert, Pfeiffer and Saethre-Chotzen syndromes (acro-ce- phalo-syndactyl types 1, 5 and 3, respectively) are characterized by early calcification of the cranial sutures that causes hypoplasia of the that cause hypoplasia of the mid-face. In these cases, the facial skeletal appears to demonstrate mandibular prognathism 


\section{Case 2}

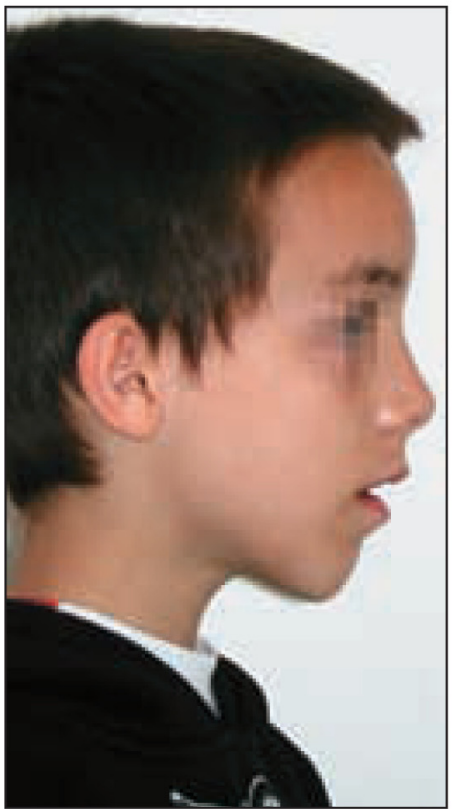

a

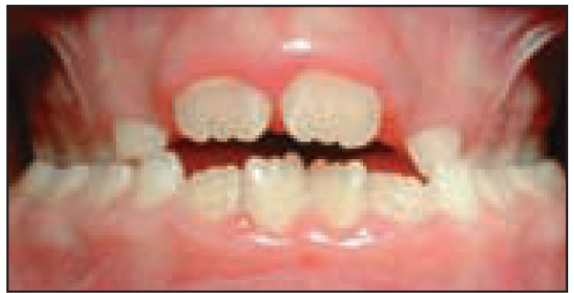

C

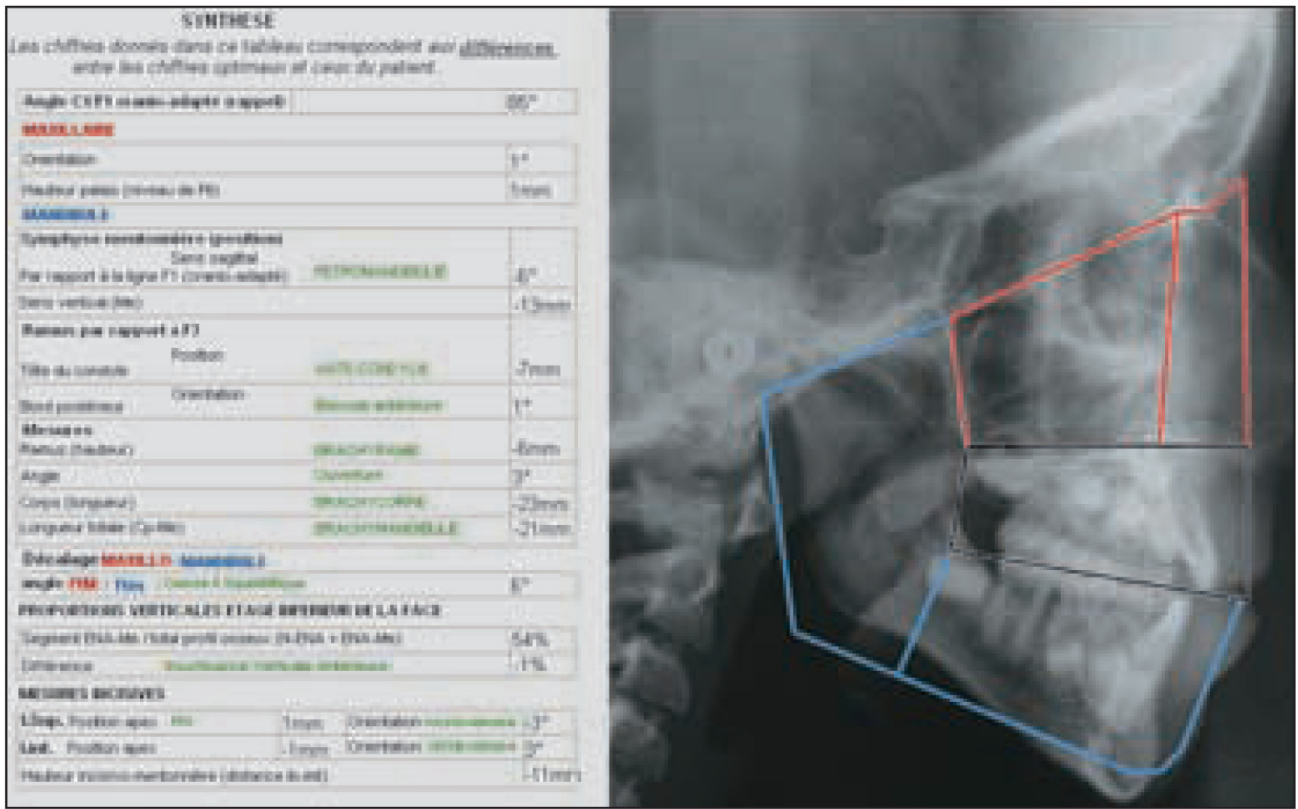

b

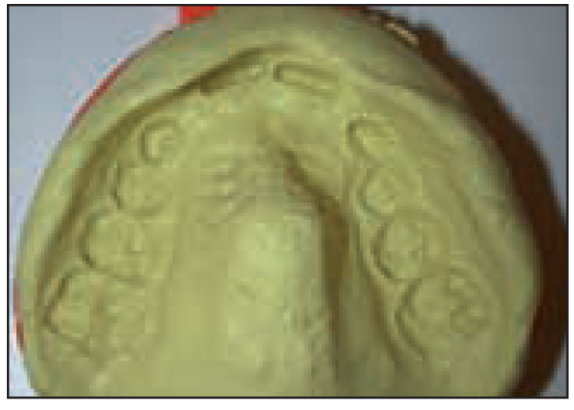

e

Cranio-facial morphology in the OSAS "type"

a and $b$ : This patient, an 8 year-old boy, suffered from attention deficit disorder, hyperactivity, and agitated sleep with constant snoring interrupted by pauses in breathing. In addition to his long face with rings under his eyes, lip closure was strained, his profile retrusive and reflective of a hyper-divergent typology (Delaire's architectural analysis computerized by means of the Tridim ${ }^{\mathrm{TM}}$ program);

$c$ to e: the intra-oral examination showed a deep, high arch palate, with bilateral cross bite, anterior infraclusion, and a Class II tendency.

because of the collapse of the nasomaxillary complex and the development of a Class III malocclusion. If the defects of these children are treated early with neuro-surgery to eliminate the intra-cranial hypertension associated with sutural calcification, it is probable that OSAS would be further under-estimated, suspected as it is in $50 \%$ of the subjects ${ }^{15,24}$. 


\section{Case 3}

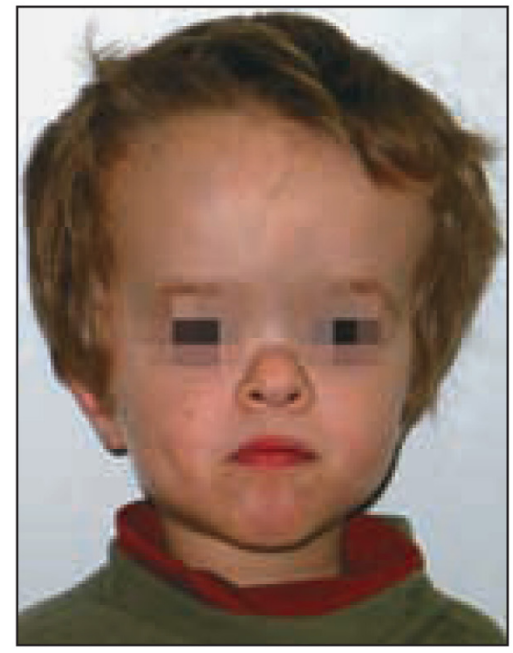

a

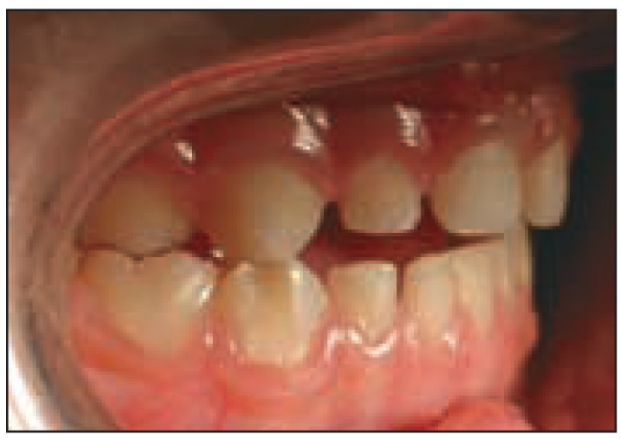

c

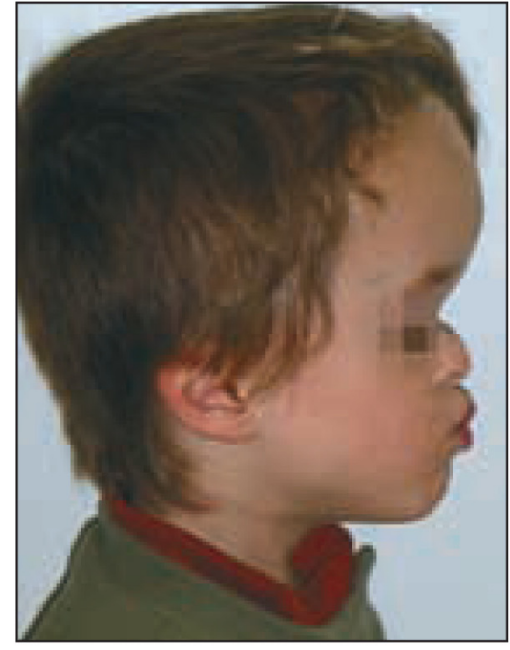

b

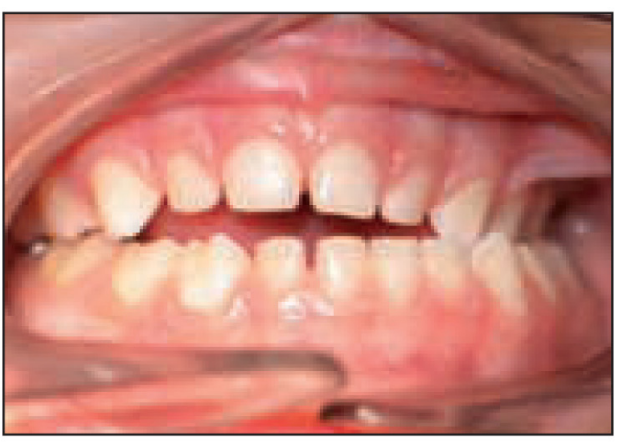

d

$a$ and b: this 4 year-old boy, afflicted with achondroplasia, also had persistent OSAS symptoms despite previous adeno-tonsillectomy. Visual examination showed facial retrusion, with caved-in nasal appearance, accentuated by hydrocephaly;

$c$ and $d$ : intra-oral examination revealed a Class II malocclusion with uni-lateral cross bite associated with symmetrical maxillary insufficiency with lateral deviation.

In trisomy 21 (Downs syndrome) early calcification of the spheno-occipital suture, hypoplasia of the mid-face (reduction of palatal length and width), and a diminishing of the cranial base are all found. Relative macroglossia associated with the syndrome which constitutes an additional risk factor for OSAS $^{9}$, affects half of these patients ${ }^{6}$.

Children afflicted with achondroplasia, inherited through autosomal dominance, suffer from dwarfism, under-development of the maxilla and the mandible, as well as from 
functional aberrations that favor obstructive sleep disturbance ${ }^{15,22}$. In the case shown in figure 3 , the three yearold patient, came in for consultation because of persistence of OSAS problems even though excess tonsillar tissue had already been removed. On examination we noted that his face displayed the typical characteristics of the syndrome, a deep sinking in of the bulk of the middle face, associated with hydrocephaly that had been treated by tapping of the cephalorachidian fluids (case 3 ).

\section{2 - 2 - 2- Syndrome involving the mandible}

Characteristics of Robin's syndrome are symmetrical under-development of the mandible (that diminishes the height of the rami and the length of the body and affects the orientation of the condyles), associated with a palatal cleft and glossoptosis that severely obstructs breathing capacity beginning at birth. In the Nager syndrome and in the Franceschetti or TreacherCollins syndrome the principal defects are maxillo-facial dystosis and underdevelopment of the mandibular rami and condyles, the net result being an increase in facial height that promotes oropharyngeal blockage ${ }^{15}$.

While changes in position can be effective in preventing backward tilting of the tongue, in half the cases the obstruction has to be dealt with mechanically or surgically with intubation, tracheotomy, surgical osteo-distraction of the mandible, or a surgical glossopexy that produces a temporary adhesion of the mucosal tissues of the tongue to the lower lip ${ }^{8}$. Some treatment teams used intra-oral appliances, based on the monobloc that Pierre Robin introduced, to unblock the pharynx mechanically as the mandible is propelled forward 4 .

\section{3 - INTERRELATIONSHIP BETWEEN OSAS TREATMENT AND CRANIO-FACIAL GROWTH}

\section{3 - 1 - Continuous Positive Airway Pressure (CPAP)}

Continuous Positive Airway Pressure is a non-invasive but effective means of treating OSAS that employs a nasal mask through which a compressor delivers a positive pressure that keeps the airways open no matter what sleeping posture the child assumes. The device whose nasal face mask is supported by head straps is cumbersome to wear and some patients, supported by their parents, find it difficult to wear. These non- compliant patients seldom use the device and end up by abandoning it ${ }^{19}$.

So the continuous airway pressure system is usually reserved for patients with severe sleep apnea, those who are grossly obese, have anomalous neuro-muscular tone, are waiting for surgery, or for whom tonsillectomy or adenoidectomy has failed to relieve the problem.

Most children with sleep apnea do not require long term CPAP treatment so its effects on maxillary development are, in theory, limited but they 


\section{Case 4}
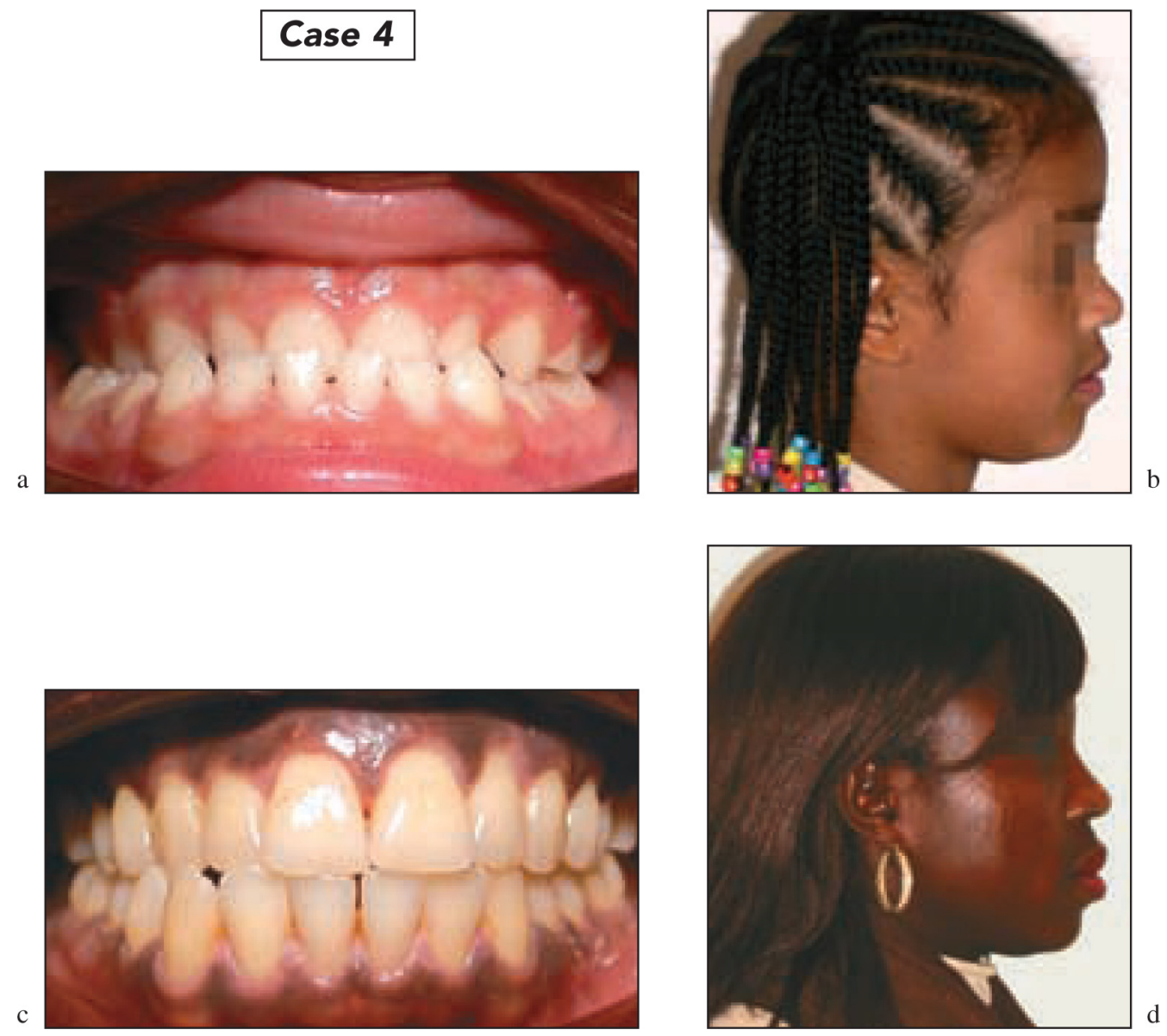

Familial predisposition to Class III protrusion and development of anterior cross bite after wearing a VPPC mask. $a$ and b: Karla 5 years old;

$c$ and $d$ : her mother.

are, nevertheless, not always entirely inconsequential. Analyses of clinical cases have shown that prolonged application of CPAP forces on the facial skeletal tends to promote the development of Class III malocclusions, especially in children who are predisposed to them (case 4). The authors believe that a maxillo-facial evaluation of patients at risk is a necessity and might show the need for the use of a Delaire mask, adjusted to the assemblage of the CPAP to counterbalance the incipient deformation $^{16}$.

\section{3 - 2 - Tonsillectomy, adenoidectomy}

A recently conducted systematic review with meta-analysis (Bonuck et $\left.a l^{3}{ }^{3}, 2009\right)$ endeavored to determine the effect of a combination of tonsillectomy and adenoidectomy on growth and its bio-markers. OSAS 
and other sleep respiratory disorders can produce retardation or a break in growth rates by interfering with normal nocturnal secretion of the somatotropic hormone, the $\mathrm{GH}$ or growth hormone.

After surgery, a significant increase in the serum levels of molecular $\mathrm{GH}$ mediators has been noted, the insulinlike growth factor I (IGF I) and IGFBP-3 (binding protein), along with an increase in height and weight, sometimes sufficient, in a "catch-up" effect, to restore the patient to normal body growth.

One team devoted itself to studying the repercussion of OSAS on craniofacial growth ${ }^{31}$, by comparing over a five year period the morphology of a group of children with sleep apnea, treated with tonsillectomy and adenoidectomy, to a control group of children with no breathing problems. Before treatment, at an average age of 5.5 years, they found significant differences between the apnea patients and the control group, as revealed by cephalometric analyses. The apnea patients had mandibles that were more inclined posteriorly and maxillae that were more tilted anteriorly. They had an increase in anterior facial height, the anterior portions of their cranial bases were shorter, their upper and lower incisors tilted more lingually, and nasal areas that did not jut as far forward. But five years after treatment, the authors found no significant differences between the two groups except for length of the cranial base and of the nose both of which remained shorter for the apnea patients than for the control group.

A possible explanation for these results is that muscular equilibrium changed after the nasal obstruction was removed thus spontaneously restoring contact between upper and lower lips, allowing tongue position to rise, and restoring better head posture, all effects that have been repeatedly described since the first studies on breathing were conducted. But a Swiss orthodontist has formulated an alternative hypothesis in evaluating these results ${ }^{23}$, asserting that the schema of the posterior mandibular rotation in young OSAS patients results from a decrease in ramal growth, development of the condylar cartilage having slowed down because of a decrease in serum $\mathrm{GH}$, growth hormone levels.

\section{3 - 3 - Rapid palatal expansion}

The work of Linder-Aronson and Woodside, cited by Villa ${ }^{30}$, described the effects of rapid palatal expansion on breathing even before the identification of obstructive sleep apnea in children. This orthopedic treatment produced a significant increase in the area of the nasal fossas and a 36.2 to $45 \%$ reduction in nasal resistance. The creation of additional space for the tongue helped, secondarily, to open up the oropharynx. In his studyVilla ${ }^{30}$ proposed to evaluate rapid maxillary expansion in the treatment of OSAS, using a sample of children 4 to 11 years old, selected in accordance with three criteria:

- the existence of a malocclusion, with a deep and narrow vaulted palate associated with overbite in a Class II relationship or anterior cross bite;

- OSAS symptoms, with habitual snoring and pauses in respiration, sleep that is not restorative, an 
apnea-hypopnea per hour (AHI) > 1 per hour, as measured by poly-somnography;

- refusal of parents to have tonsillectomy and adenoidectomy performed on their child.

The investigators excluded from their list subjects who were obese, had cardio-respiratory or neuro-muscular problems, had severe craniofacial anomalies, or presented severe symptoms. The rapid expander was soldered to two bands that were cemented to the maxillary second temporary molars and was activated by two turns for the first 10 days until the palatal cusps of the upper molars were in contact with the buccal cusps of their mandibular antagonists.

The extent of expansion achieved was an average of $3.7+\mathrm{mm}$ in the canine region and $5.0+2.2 \mathrm{~mm}$ in the molar region. In a 12 month fixed retention period the over-correction was maintained. The AHI decreased significantly after treatment, dropping from $5.8 \pm 6.8$ to $1.5 \pm 1.6(p=0.005)$, together with an improvement in the index of oxygen saturation and the index of arousal from sleep. It should be noted that the change in $\mathrm{AHI}$ differed as a function of the type of malocclusion, being greater with children with Class II overjet and overbite than with children who had cross bites. For two patients $(14,3 \%)$, the rapid palatal expansion had no effect on $\mathrm{AHI}$, the authors attributing this to major anatomical blockages, a nasal septum deviation in one child and marked hypertrophy of palatal soft tissue that was repeatedly re-infected in the other.

In order to evaluate the contribution to the treatment result maxillo-facial orthopedics had played alongside ENT surgery Guilleminault et al) reviewed the records of 32 patients, from 4 to 9 year old, who needed removal of excess tonsilar and adenoidal tissue as well as orthodontic treatment and presented a moderate OSAS condition, as defined by their having a minimal oxygen saturation level of $90 \%$, and an IAH of less than 20 per hour. The children were divided into two groups, the first receiving surgical treatment before the rapid palatal expansion and the other the same therapies in reverse order. The results, evaluated by questionnaire and with polysomnographic readings taken at the time of diagnosis and between three and six months after each therapeutic procedure had been completed, showed that $87.5 \%$ of the patients required both types of treatment. Surgery alone did not correct the OSAS completely and in only two patients did the OSAS symptoms disappear after only orthodontic treatment. For two patients the apnea condition continued unabated despite their having received both therapies.

In this study, in which some patients also received mandibular expansion, the maxillary expansion was accomplished with the opening of the orthopedic device a quarter of a millimeter per day. Both fixed and removable appliances were used depending on the clinical situation and the preference of the orthodontist.

\section{3 - 4 - Mandibular advancement oral devices ${ }^{30}$}

Mandibular advancement appliances, designed like orthopedic activators, free up the pharynx and 
maintain a propulsive force on the mandible, thus keeping palatal and basal lingual soft tissues in a state of tension. Just as orthodontists use this type of device to correct Class II malocclusions in children and adolescents, therapists can be employ them to provide symptomatic treatment for snoring and OSAS in adults.

Even if the effectiveness of these devices is variable, depending upon the degree of mandibular advancement that can be obtained and the severity of any morphological disparities that may be present, oral appliances offer selected patients clinical relief that is documented by significant changes on polysomnographic records.

Certain studies have attempted to evaluate their efficacy in treating children with apnea, particularly because it has been shown that in nonobese patients the extent of maxillary overjet is associated with the severity of OSAS ${ }^{21}$. In one randomized clinical study $^{30}$, researchers treated 19 children, with an average age of 6.86 years, with an advancement appliance for 6 months and compared them to a control group of 13 untreated children with an average age of 7.34 years.

\section{4 - CONCLUSION}

While orthodontists have made evaluation of lip and tongue habits a regular component of the intake examinations they conduct on potential patients, they have not yet routinely incorporated an assessment of the quality of sleep and the presence or absence of snoring into their pretreatment record taking.
They evaluated the patients with a questionnaire, a polysomnograph, and clinical ENT and orthodontic examinations. No intraoral or cephalometric X-Rays were taken, in accord with American recommendations.

The oral appliance, made from alginate impressions, was set to an advancement reading obtained by having the children bite on wax in a forced Class I position, so that the overjet would be corrected and the mandible re-centered. In each appliance an acrylic pearl was inserted behind the incisor positions in a way that would encourage proper tongue position. Children were asked to wear the appliance at all times except when eating.

Of 19 patients treated, $87 \%$ had excessive overbite or a Class II protrusion. Even though a quarter of the patients abandoned treatment, a sixmonth evaluation showed a significant decrease in IAH ( $p=0.001)$, while this breathing variable remained constant in the control group. For $64.2 \%$ of the treated children the $\mathrm{IAH}$ dropped at least $50 \%$, showing the effectiveness of the OSAS therapy accomplished in parallel to correction of the malocclusion.

But according to some studies of the morphology of patients with obstructive respiratory difficulties, it would appear that when orthodontists assess Class II malocclusions or underdevelopment or hyper-divergence of upper or lower jaws, it is important that they determine whether or not some aspect of obstructive sleep 
apnea is implicated in the disorder before they formulate a treatment plan. Conclusions of research studies can sometimes be fragile, in view of the small samples they consider, but it is clear that rapid palatal expansion or mandibular advancement can be at- tractive alternatives to or useful adjuncts to ENT surgery. More and more frequently, orthodontists are now being asked to begin early treatment of patients afflicted with sleep apnea, sometimes for patients still in the temporary dentition stage.

\section{REFERENCES}

1. Agence nationale d'accréditation et d'évaluation en santé. Évaluation clinique et économique de la chirurgie dans le traitement du syndrome des apnées obstructives du sommeil. Paris: Anaes; 1999.

2. American Academy of Pediatrics (AAP). Subcommittee on Obstructive Sleep Apnea Syndrome. Clinical practice guideline: diagnosis and management of childhood obstructive sleep apnea syndrome. Pediatrics 2002;109(4):704-12.

3. Bonuck KA, Freeman K, Henderson J. Growth and growth biomarker changes after adenotonsillectomy: systematic review and meta-analysis. Arch Dis Child. 2009 Feb;94(2):83-91.

4. Buchenau W, Urschitz MS, Sautermeister J, Bacher M, Herberts T, Arand J, Poets CF. A randomized clinical trial of a new orthodontic appliance to improve upper airway obstruction in infants with Pierre Robin sequence. J Pediatr. 2007 Aug;151(2):145-9.

5. Carvalho FR, Lentini-Oliveira D, Machado MA, Prado GF, Prado LB, Saconato H. Oral appliances and functional orthopaedic appliances for obstructive sleep apnoea in children. Cochrane Database Syst Rev. 2007 Apr 18;(2):CD005520.

6. De Miguel-Diez J, Villa-Asensi JR, Alvarez-Sala JL. Prevalence of sleep-disordered breathing in children with Down syndrome: polygraphic findings in 108 children. Sleep. 2003 Dec 15;26(8): 1006-9.

7. Defabjanis P. Impact of nasal airway obstruction on dentofacial development and sleep disturbances in children: preliminary notes. J Clin Ped Dent 2003;27(2):95-100.

8. Denny AD, Amm CA, Schaefer RB. Outcomes of tongue-lip adhesion for neonatal respiratory distress caused by Pierre Robin sequence. J Craniofac Surg. 2004 Sep;15(5):819-23.

9. Donnelly LF, Shott SR, LaRose CR, Chini BA, Amin RS. Causes of persistent obstructive sleep apnea despite previous tonsillectomy and adenoidectomy in children with down syndrome as depicted on static and dynamic cine MRI. AJR Am J Roentgenol. 2004 Jul;183(1):175-81. Links

10. Guilleminault C, Li KK, Khramstov A, Pelayo R, Martnez S. Sleep disordered breathing: surgical outcomes in prepubertal children. Laryngoscope 2004;14(1):132-7.

11. Guilleminault C, Pelayo R, Leger D, Clerk A, Bocian RC. Recognition of sleepdisordered breathing in children. Pediatrics 1996;98:871-882.

12. Guilleminault C, Quo S, Huynh NT, Li K. Orthodontic expansion treatment and adenotonsillectomy in the treatment of obstructive sleep apnea in prepubertal children. Sleep 2008;31(7):953-957.

13. Guilleminault C, PartinenM, Praud JP, Quera-SalvaMA, Powell N, Riley R. Morphometric facial changes and obstructive sleep apnea in adolescents. J Pediatr.1989;114(6):997-9.

14. Guilleminault $C$, Stoohs R. Chronic snoring and obstructive sleep apnea syndrome in children. Lung 1990;168 Suppl:912-9.

15. Jamieson A, Guilleminault C, Partinen M, Quera-Salva MA. Obstructive sleep apneic patients have craniomandibular abnormalities. Sleep 1986;9:469-77. 
16. Kasey K. Li, Robert W. Riley, Guilleminault C. An Unreported Risk in the Use of Home Nasal Continuous Positive Airway Pressure and Home Nasal Ventilation in Children Mid-Face Hypoplasia Chest 2000;117:916-918.

17. Kawashima S, Peltomäki T, Sakata H, Mori K, Happonen RP, Rönning O. Craniofacial morphology in preschool children with sleep-related breathing disorder and hypertrophy of tonsils. Acta Paediatr. 2002;91(1):71-7.

18. Lim J, McKean M. Adenotonsillectomy for obstructive sleep apnoea in children. Cochrane Database Syst Rev. 2003;(1):CD003136.

19. Lumeng JC, Chervin DR. Epidemiology of pediatric obstructive sleep apnea. Proc Am Thorac Soc 2008;5:242-252.

20. Marcus CL, Rosen G, Ward SL, Halbower AC, Sterni L, Lutz J, Stading PJ, Bolduc D, Gordon N. Adherence to and effectiveness of positive airway pressure therapy in children with obstructive sleep apnea. Pediatrics. 2006 Mar;117(3):e442-51.

21. Miyao E, Noda A, Miyao M, Yasuma F, Inafuku S. The role of malocclusion in nonobese patients with obstructive sleep apnea syndrome. Intern Med. 2008;47(18):15738. Epub 2008 Sep 16

22. Onodera K, Niikuni N, Chigono T, Nakajima I, Sakata H, Motizuki H. Sleep disordered breathing in children with achondroplasia. Part 2. Relationship with craniofacial and airway morphology. Int J Pediatr Otorhinolaryngol. 2006 Mar;70(3):453-61.

23. Peltomäki T. The effect of mode of breathing on craniofacial growth-revisited. Eur $J$ Orthod. 2007 Oct;29(5):426-9. Epub 2007 Sep 4.

24. Pijpers M, Poels PJ, Vaandrager JM, de Hoog M, van den Berg S, Hoeve HJ, Joosten $\mathrm{KF}$. Undiagnosed obstructive sleep apnea syndrome in children with syndromal craniofacial synostosis. J Craniofac Surg. 2004 Jul;15(4):670-4. Links.

25. Pirilä-Parkkinen K, Pirttiniemi $P$, Nieminen P, Tolonen U, Pelttari U, Löppönen H. Dental arch morphology in children with sleep-disordered breathing. Eur J Orthod. 2009 Apr;31(2):160-7.

26. Rees K, Wright A, Keeling JW, Douglas NJ. Facial structure in the sudden infant death syndrome: case control study. Br Med J 1998;317:179-180.

27. Robinson P. D,Waters K. Are children just small adults? The differences between paediatric and adult sleep medicine. Internal Medicine Journal (2008).

28. Shintani T, Asakura K, Kataura A. The effect of adenotonsillectomy in children with OSA. Int J Ped Otorhinolaryngology 1998;44(1):51-8.

29. Villa MP, Bernkopf E, Pagani J, Broia V, Montesano M, Ronchetti R. Randomized controlled study of an oral jaw-positioning appliance for the treatment of obstructive sleep apnea in children with malocclusion. Am J Respir Crit Care Med Vol 165. pp 123127, 2002.

30. Villa MP, Malagola C, Pagani J, Montesano M, Rizzoli A, Guilleminault C, Ronchetti R. Rapid maxillary expansion in children with obstructive sleep apnea syndrome: 12month follow-up q. Sleep Med. 2007 Mar;8(2):128-34.

31. Zettergren-Wijk L, Carl-Magnus Forsberg and Sten Linder-Aronson. Changes in dentofacial morphology after adeno-/tonsillectomy in young children with obstructive sleep apnoea - a 5-year follow-up study. Eur J Orthod 28 (2006) 319-326.

32. Zucconi M, Caprioglio A, Calori G, et. al. Craniofacial modifications in children with habitual snoring and obstructive sleep apnoea: a case-control study. Eur Respir J 1999;13:411-417. 